\section{Simulation of the pneumatic} behavior in the virtual commissioning of automated assembly systems

\section{Anton Strahilov ${ }^{*}$}

Dennis Éffmert

Jivka Ovtcharova

Thomas Bär

'Department DAIMLER AG · UIm, 89077, Germany

Currently, the development of complex automated production stations will almost be impossible without the use of computer aided simulation. So as to increase the reliability of such simulations, the simulation models must depict the reality as much as possible. Including the physical properties of the elements in the models allows for an increase in realism of the simulation. One of the aspects in this field is the pneumatic behavior of pneumatic drives. Using physics based simulation approaches of the video game industry, a realtime assemproaches or the video game indstry areatline assembly station simulation for the virtualcommissioning considering the pneumatic behavior of the pneumatic drive was developed. This paper presents how the underlying model was developed and the extent to which different simulation factors have an influence on the pneumatic behavior.

\section{An innovative framework for the simulation of manufacturing systems: an application to the footwear industry}

Alexandra F. Marques"

Miguel Mujica ${ }^{3}$

Jorge Pinho de Sousa',2

Paulo Sá Marques'

Rui Rebelo

António C. Alves'

IInesc Tec · Porto, Portuga

\section{University of Porto}

Porto, Portugal

University of Barcelona, Spain

Simulation in industrial environments has been recognized as a valuable approach for capturing the different characteristics and complexity of the dynamics in industrial processes. However, there is a clear need for preading the use of simulation tools in manufacturin compan in ing in terms of the specific skills of the modellers an in terms of the time needed to develop models that ar effectively useful in actual manufacturing systems. Th slow modelling process often precludes the use of simulation for facing the operational problems that rise in the day-to-day operations. This paper presents a brie overview of the use of simulation tools in manufacturing. and focus on the development of an innovative imution frat on the dect on libraries of components inume and modus. This fram ing the learning curve in developing simulation models for manufacturing and logistics systems. The requirements and advantages of this novel modular modelling approach are presented and discussed in the context of a case study that uses the SIMIO software for simulating the production and logistics systems of a generic footwear manufacturing system in Portugal.
Modeling and simulation of

a laser scamner sensor: an industriall application case

\section{study}

José Lima'

José Gonçalves

Paulo J. Costa

A. Paulo Moreira

'INESC TEC (formerly INESC Porto) and Polytechnic Institute of Bragança, Portugal

INESC TEC (formerly INESC Porto) and Faculty of Engineering, University of Porto, Portugal

A laser scanner is a popular sensor widely used in industry and mobile robots applications that measures the distance to the sensor on a slice of the plan. At the same time, simulation has becoming more and more used in industries and academia since it presents several advantages. It takes the building and rebuilding phase out of the loop by using the model already created in the design phase. Further, simulation time on testing is cheaper and faster than performing the multiple tests of the design each time. Besides, it is easier to measure some variabs in simution than in

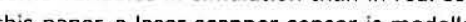
this paper, a laser scanner sensor is modelled and implemented in a developed simulator that already has several other sensors and actuators models. The presented simulation reflects the laser model properties such as target colour dependences, noise, limits, time constraints and target angle functions. As a case study, the same scenario is assembled with real components on a conveyor belt and in simulation. Results from both approaches are compared and validate the proposed model methodolo As an example a 3D object moch recognition task is addressed highlighting the developed realistic model. Further industrial and R\&D implementations based on this sensor could be stressed in simulation before implementation.

\section{On the Application of Discrete-event Simulation in Production}

Farhad Norouzilame1, 2*

Mats Jackson

IIndustrial PhD · LEAX Group

Köping, Vàstmanland, 731 36, Sweden

2Department of Innovation, Design and Technology -

University or Malardalen

Eskilstuna, Södermanland, 631 05, Sweden

The current fierce competition within the manufacturing industry throughout the world is a result of globalisation and dynamic changes in the market. This new era within the production world requires shorter lead times, integrated logistics, capabilities regarding handling changes in product volumes and variety, as well as conformity to environmental rules and regulations legislated by governments and organizations. Apparently, the multitude of variables needed to solve problems complicates the decisionmaking process. In order to provide solutions for complex problem solving within production development which include many variables and a certain amount f uncertainty there is a need for robust decision Discreterent sim of the virtual tools that can be used as a support for decision-making for production related problems. Th current paper addresses challenges which cause low utilization of DES in industry along with a framework for handling those challenges and performing DES projects in an effective and efficient way.
Corresponding author: anton strahilovedaimlercom copyright $O 2013$ springer hor: jose.lima (winescporto.pt

copyright @ 2013 Springer
- Corresponding author: farhad.noruzi@gmail.com copyright $@ 2013$ Springer 